\title{
Kawasaki Disease: Experience from Developing Countries
}

\author{
Somsri Wiwanitkit ${ }^{1}$ - Viroj Wiwanitkit ${ }^{2}$
}

Received: 7 October 2015 / Accepted: 29 October 2015 / Published online: 4 December 2015

(C) Dr. K C Chaudhuri Foundation 2015

To the Editor: The recent article on Kawasaki Disease (KD) by Singh et al. is very interesting. Singh et al. made an important concern that "IVIg is an expensive product and poses several difficulties for patients of KD in developing countries who may find it difficult to access therapy even if a diagnosis of KD has been made in time [1]." In fact, the problem of cost for management of several pediatric diseases is a common problem in poor developing countries. Here, we would like to share our view from Thailand, another developing country in Southeast Asia. In Thailand, the incidence of KD is "from 2.14 to 3.43 cases per 100,000 children aged $0-5 \mathrm{y}$ " and the problem of IVIg resistance is common [2]. Considering the cost of case management, the similar problem is observed. There is an interesting medical economics analysis by Arj-ong et al. who concluded that treatment of all Kawasaki disease cases in Thailand with IVIg is likely to result in lower cost and better outcome when compared to no treatment with the IVIg policy [3]. In addition, the attempt to develop "locally produced intravenous immunoglobulin" is reported and this is expected to be an alternative way to lower the cost for Kawasaki Disease case management in Thailand [4].
Conflict of Interest None.

Source of Funding None.

\section{References}

1. Singh S, Sharma A, Jiao F. Kawasaki disease: issues in diagnosis and treatment - a developing country perspective. Indian J Pediatr. 2015. doi:10.1007/s12098-015-1890-4.

2. Durongpisitkul K, Sangtawesin C, Khongphatthanayopthin A, et al. Epidemiologic study of Kawasaki disease and cases resistant to IVIG therapy in Thailand. Asian Pac J Allergy Immunol. 2006;24:27-32.

3. Arj-ong S, Chotivitayatarakorn P, Lertsapcharoen $\mathrm{P}$, Khongphatthanayothin A, Thisyakorn C. A cost-benefit analysis of intravenous immunoglobulin treatment in children with kawasakidisease. J Med Assoc Thail. 2003;86:S179-88.

4. Sangtawesin C, Kirawitaya T, Layangkool T, Nawasiri W, Vimolsarawong N. Treatment of Kawasaki disease using locally product intravenous immunoglobulin. J Med Assoc Thail. 2003;86:S656-60.

Somsri Wiwanitkit

somsriwiwan@hotmail.com

1 Wiwanitkit House, Bangkhae, Bangkok 10160, Thailand

2 Hainan Medical University, Haikou, China 